\title{
Tree Structure and Pruning Response of Six Peach Growth Forms
}

\author{
D. Bassi and A. Dima \\ Dipartimento di Colture Arboree, Università degli Studi di Bologna, V. Filippo Re 6, Bologna 40126, Italy \\ R. Scorza \\ U.S. Department of Agriculture, Agricultural Research Service, Appalachian Fruit Research Station, \\ Kearneysville, WV 25430
}

Additional index words. Prunus persica, growth habit, training system

\begin{abstract}
The response of young, nonbearing peach [Prunus persica (L.) Batsch] trees to pruning was studied in six distinct growth forms including semidwarf, spur-type, upright, columnar or pillar, weeping, and standard. Two years after field planting, pillar and upright trees were trained to slender spindle. Semidwarf, spur-type, and standard trees were trained to the open or delayed vase form. Weeping trees were pruned in a manner similar to the Lepage hedge for pear. Branch density before pruning was highest in semidwarf, spur-type, and upright trees and lowest in pillar trees. Standard, semidwarf, and spur-type trees reacted similarly to pruning, but semidwarf trees produced as much wood in the following season as had been pruned off, and produced large numbers of fruiting branches. The small size of semidwarf trees suggested their use for medium-density plantings (MDPs). Pillar trees needed only light pruning. No major cuts were necessary and many fruiting branches were produced even on nonpruned trees. The pillar canopy was $60 \%$ thinner and required $50 \%$ fewer pruning cuts than the standard canopy and may be particularly suited to high-density plantings (HDPs). The upper canopy of weeping trees grew more than most other forms. They were intermediate in branch density and required an intermediate amount of pruning. Most striking was the unique canopy form of weeping trees, which may be used in developing new training systems. The results of this study suggest that new growth forms have the potential to reduce pruning and training requirements for peach, particularly in MDPs and HDPs. This potential suggests further investigation and exploitation of alternate peach tree growth forms.
\end{abstract}

Peach production today depends entirely on standard tree cultivars. A standard tree is developmentally characterized by 1 year-old fruiting branches (FBs), moderately strong apical dominance, and vigorous acropetal growth. Severe winter pruning, which often removes $60 \%$ of the annual growth, is required to stimulate the development of new shoots and to ensure that fruiting shoots develop throughout the canopy. Summer pruning is required to remove excess growth following winter pruning (Baldini, 1965; Corelli-Grappadelli and Sansavini, 1991; Morettini, 1943; Ryugo, 1988). In the absence of acceptable dwarfing rootstocks high-density plantings (HDPs) are often impaired by the excessive vigor of standard cultivars. Less vigorous trees might reduce the amount of pruning required to control excessive growth. Mediumdensity plantings (MDPs) would also benefit from the introduction of trees that are small and easy to manage or that need limited pruning.

Several tree forms other than the standard form are known, including the dwarf, compact, pillar, and weeping types (Scorza, 1988). The horticultural potential of peach genotypes featuring unique or reduced tree growth has been reported (Scorza et al., 1984). Small cultivars such as the brachytic dwarf with potential for HDPs have been studied (Hansche et al., 1979). The commercial exploitation of dwarf cultivars has been impeded because of their dense canopy and poor fruit quality (DeJong and Doyle, 1984; Fideghelli et al., 1991; Scorza, 1988). The impact of new dwarf cultivars with better fruit quality (Hansche, 1989) remains to be seen. Other tree forms with canopies intermediate between

Received for publication 8 Mar. 1993. Accepted for publication 26 July 1993. Research made possible by a grant from the Italian National Research Council, Rome. We are grateful to B. Marangoni for his assistance in planning the training systems and S. Martelli for his technical expertise. The cost of publishing this paper was defrayed in part by the payment of page charges. Under postal regulations, this paper therefore must be hereby marked advertisement solely to indicate this fact. the standard and the compact, such as semidwarf and semicompact, show promise (Quarta and Scortichini, 1985).

The lack of adapted, size-controlling rootstocks for peach (Marangoni et al., 1984) accentuates the need for new easy-to-train cultivars. Marini (1985) reported that tree vigor and cultivar affect pruning response of standard trees. The fact that different peach tree growth forms react differently to the same pruning system has been established (DeJong and Doyle, 1984; Scorza et al., 1984, 1986). The present study was undertaken to assess the ease of training several tree growth forms and to evaluate shoot growth following pruning using pruning systems appropriate for each growth form.

\section{Materials and Methods}

Five phenotypically distinct peach tree growth types were compared to the standard cultivar Suncrest. The genotypes tested were (Fig. 1) a) IF 7030087, a semidwarf tree, selected from openpollinated 'Redhaven', that is somewhat shorter and less vigorous than a standard tree (Fideghelli et al., 1979); b) KV 77107, a cross between the dwarf 'Empress' and 'Com-Pact Redhaven', which has a small canopy and, if nonpruned or lightly pruned, develops many spurs (spur-type); c) KV 84091, an upright tree resulting from a cross between the compact 'KV 77119' and 'NJ Pillar' ['NJ Pillar' is a genotype with a slender and broomy canopy caused by narrow branch angles, vertically growing branches, and thin 1year-old branches]; d) 'Italian Pillar', which has a slender, columnar canopy resembling 'NJ Pillar', except with somewhat thicker branches; and e) PI 41459, which is a weeping tree with pendulous branches.

All genotypes were budded in Aug. 1987 on 'Ps. A 5' peach, which produces uniform seedlings. The budded trees were planted in Nov. 1988 at the Univ. of Bologna's Cadriano Experimental Station. Nine trees per genotype were planted $4.3 \mathrm{~m}$ apart in rows 

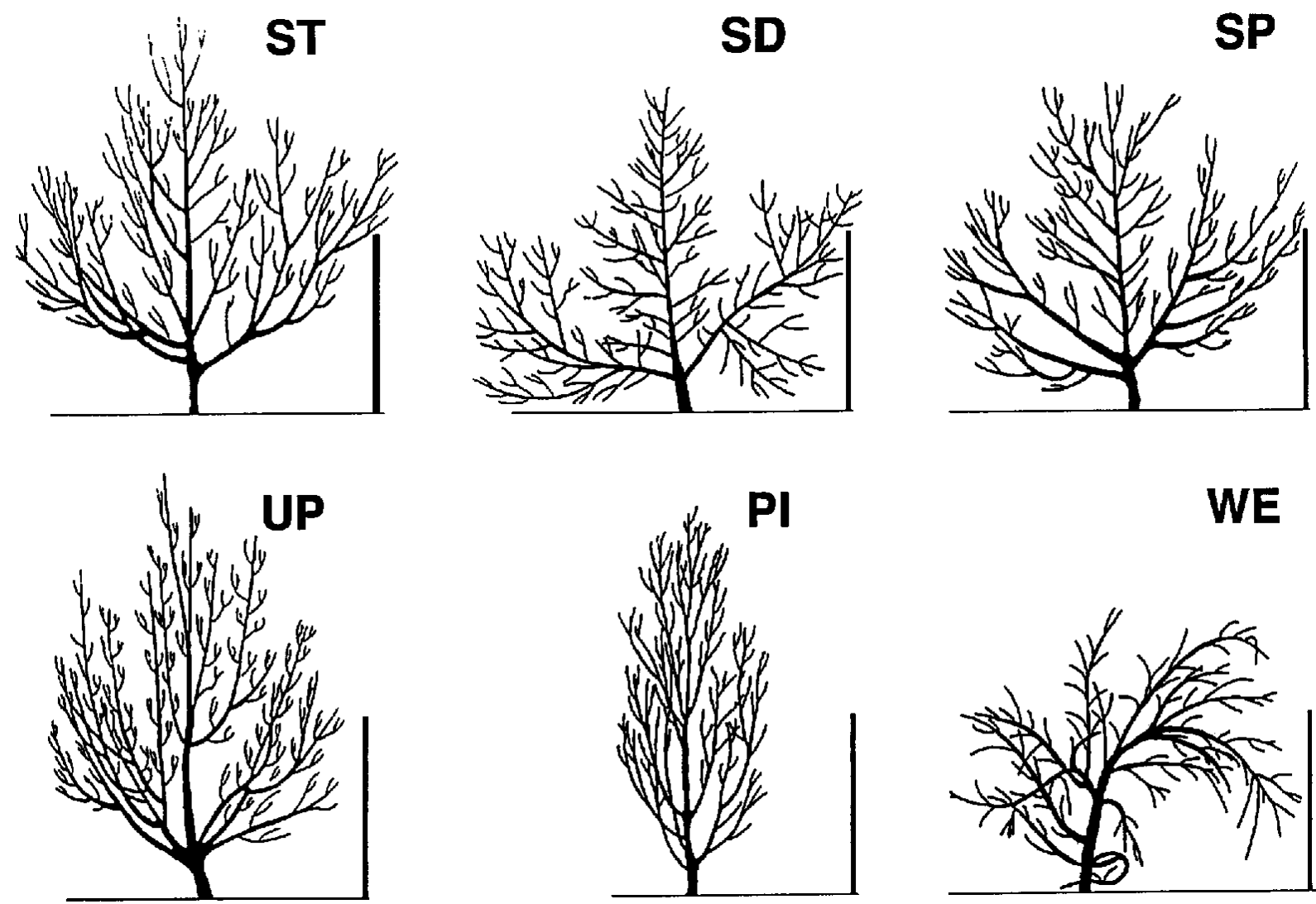

\section{WE}

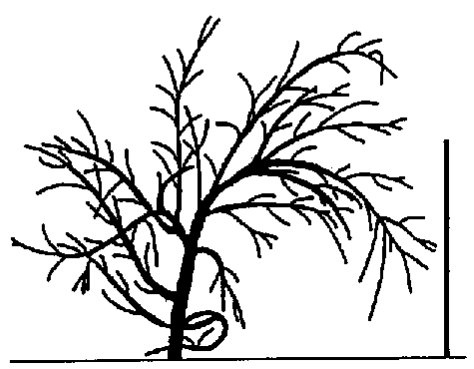

Fig. 1. Nonpruned trees of six peach growth types after 2 years of growth; $\mathrm{ST}=$ standard, $\mathrm{SD}=$ semidwarf, $\mathrm{SP}=$ spur-type, $\mathrm{UP}=$ upright, $\mathrm{PI}=$ pillar $($ columnar $)$, and WE = weeping.

$3.0 \mathrm{~m}$ apart in a completely randomized design with three, threetree replicates and within-row border trees. Trees were pruned 10 $\mathrm{cm}$ above the bud union before the growing season to establish uniformity and to allow growth to develop from a single shoot. Trees were not pruned during 1989 or 1990 so they could develop their distinct form. At this time, an appropriate training system was selected for each growth habit.

At the end of the second growing season (1990), the trunk diameter $10 \mathrm{~cm}$ above the bud union, the crown diameter at maximum width, and tree height above the bud union were measured. The number of laterals produced from each of six trees per genotype during the first growing season was recorded. Two laterals were chosen from the upper and two from the lower half of each tree canopy and measured after the second year for length of first- and second-year growth and length and angle of second-order branches.

After the second year, six trees per genotype were winterpruned to conform to specific training systems. The slender spindle, or fusette, was adopted for the columnar and upright forms. The columnar trees were thinned by removing 1- and 2year-old branches because vigorous limbs were nearly absent. Strong 2-year-old upright branches on the upright were cut back to 1-year-old branches rather than thinned to reinforce dominance of the central leader. The open, delayed vase was adopted for the semidwarf, spur-type, and standard forms. This system differed from the standard open-center vase in that the cuts were made later in tree development. The central leader was cut back to the first vigorous limb to stimulate wide angles on lower branches subsequently selected as scaffolds. Also, limbs were cut back to a lateral branch to promote the growth of fruiting branches and to prevent bare wood from forming in the center of the canopy. The weeping habit involved pruning unique to the pendulous growth form. As weeping branches grew horizontally before drooping, they were cut back to the first vigorous lateral growing upward to substitute for the branch removed. This system resembles the Lepage hedge once used in pear (Baldini, 1965), although we developed a threedimensional branch distribution pattern. The number of cuts and the amount of wood removed were recorded for each tree. Three trees of each growth form were not pruned.

One year after pruning, after the third growing season (1991), all trees were cut down above the bud union. The previous season's shoot growth was removed from the six pruned and three nonpruned trees of each growth form. All 1-year-old branches were weighed fresh. FBs at least $50 \mathrm{~cm}$ long were then separated. These were considered to be the best shoots from which to produce goodsized fruit, because a positive relationship between branch vigor and fruit size has been reported in standard peach (Corelli-Grappadelli and Coston, 1991). Length, angle, and internode length of five branches per genotype were also measured. The weight of the wood removed was normalized by dividing by trunk cross-sectional area (TCSA) to reduce bias from individual tree vigor. Fruit yields were recorded but not statistically compared between growth forms due to the great differences in fruit size between improved and unimproved genotypes. Yields between pruned and nonpruned trees within tree forms were compared. All vegetative growth data were subjected to analysis of variance, and means for variables compared between tree forms or treatments were subjected to least significant difference tests at $P=0.05$.

\section{Results}

\section{Tree morphology}

Semidwarf. After 2 years of growth, semidwarf trees were as wide as the standard trees but were $17 \%$ shorter (Table 1). The ratio 
Table 1. Comparison of tree characteristics for six peach tree growth forms after two growing seasons.

\begin{tabular}{|c|c|c|c|c|c|c|c|c|c|}
\hline \multirow{3}{*}{$\begin{array}{l}\text { Tree } \\
\text { form }\end{array}$} & \multirow[b]{3}{*}{ Genotype } & \multirow{3}{*}{$\begin{array}{l}\text { Trunk } \\
\text { diam } \\
(\mathrm{m})\end{array}$} & \multirow{3}{*}{$\begin{array}{c}\text { Canopy } \\
\text { ht } \\
(\mathrm{cm})\end{array}$} & \multirow{3}{*}{$\begin{array}{c}\text { Canopy } \\
\text { diam } \\
(\mathrm{cm})\end{array}$} & \multicolumn{3}{|c|}{ Fruiting shoot ${ }^{2}$} & \multirow{2}{*}{\multicolumn{2}{|c|}{$\begin{array}{c}\text { Nonfruiting shoots } \\
\text { (no./branch) }\end{array}$}} \\
\hline & & & & & \multirow{2}{*}{$\begin{array}{l}\text { Length } \\
(\mathrm{cm})\end{array}$} & \multirow{2}{*}{$\begin{array}{l}\text { Angle }^{y} \\
3 r d y r\end{array}$} & \multirow{2}{*}{$\begin{array}{l}\text { Internode } \\
\text { length } \\
(\mathrm{cm})\end{array}$} & & \\
\hline & & & & & & & & Upper $^{x}$ & Lower $^{\mathrm{w}}$ \\
\hline Standard & Suncrest & $62 a b^{v}$ & $210 \mathrm{~b}$ & $233 \mathrm{a}$ & $62 \mathrm{bc}$ & $45 \mathrm{bc}$ & $2.1 \mathrm{c}$ & $8 \mathrm{~b}$ & $33 a b$ \\
\hline Semidwarf & IF 7030087 & $54 \mathrm{bc}$ & $175 \mathrm{c}$ & $236 \mathrm{a}$ & $66 a b$ & $55 \mathrm{a}$ & $2.3 \mathrm{c}$ & $4 \mathrm{~b}$ & $28 \mathrm{ab}$ \\
\hline Spur-type & KV 77107 & $60 \mathrm{~b}$ & $181 \mathrm{c}$ & $221 \mathrm{a}$ & $72 \mathrm{a}$ & $48 \mathrm{~b}$ & $3.2 \mathrm{a}$ & $6 \mathrm{~b}$ & $35 \mathrm{ab}$ \\
\hline Upright & KV 84091 & $71 \mathrm{a}$ & $245 \mathrm{a}$ & $228 \mathrm{a}$ & $60 \mathrm{bc}$ & $42 \mathrm{bc}$ & $2.6 \mathrm{~b}$ & $6 \mathrm{~b}$ & $39 a$ \\
\hline Columnar & Pillar & $58 \mathrm{~b}$ & $238 \mathrm{ab}$ & $98 \mathrm{~b}$ & $54 \mathrm{c}$ & $40 \mathrm{c}$ & $2.6 \mathrm{~b}$ & $2 b$ & $4 \mathrm{c}$ \\
\hline Weeping & PI 91459 & $47 \mathrm{c}$ & $112 \mathrm{~d}^{\mathrm{u}}$ & $217 \mathrm{a}$ & $75 \mathrm{a}$ & $59 \mathrm{a}$ & $3.1 \mathrm{a}$ & $19 \mathrm{a}$ & $14 \mathrm{bc}$ \\
\hline
\end{tabular}

${ }^{\mathrm{z}}$ Base diameter $>7 \mathrm{~mm}(>6 \mathrm{~mm}$ in columnar).

${ }^{\mathrm{y}}$ Base diameter $<7 \mathrm{~mm}$ ( $<6 \mathrm{~mm}$ in columnar).

${ }^{\mathrm{x}}$ Branches from the upper half of the canopy.

${ }^{\mathrm{w}}$ Branches from the lower half of the canopy.

${ }^{v}$ Mean separation in columns by LSD at $P=0.05$

uStem length, $182 \mathrm{~cm}$.

Table 2. Branch growth in six peach growth forms after the second growing season.

\begin{tabular}{lccc}
\hline \hline & & & $\begin{array}{r}\text { 1-yr-old shoots/ } \\
\text { 2-yr-old shoots } \\
\text { Tree }\end{array}$ \\
form & \multicolumn{2}{c}{ Upper $^{\mathrm{z}} /$ lower $^{\mathrm{y}}\left(\mathrm{cm} \cdot \mathrm{cm}^{-1}\right)$} & $\begin{array}{c}\text { (lower half of } \\
\text { canopy, no./m) }\end{array}$ \\
\cline { 2 - 3 } Standard & $0.68 \mathrm{bc}^{\mathrm{x}}$ & $0.90 \mathrm{ab}$ & $16.2 \mathrm{~b}$ \\
Semidwarf & $0.60 \mathrm{c}$ & $0.90 \mathrm{ab}$ & $33.4 \mathrm{a}$ \\
Spur-type & $0.61 \mathrm{c}$ & $0.81 \mathrm{~b}$ & $35.7 \mathrm{a}$ \\
Upright & $0.78 \mathrm{abc}$ & $1.20 \mathrm{ab}$ & $41.8 \mathrm{a}$ \\
Columnar & $0.97 \mathrm{a}$ & $1.60 \mathrm{ab}$ & $8.6 \mathrm{c}$ \\
Weeping & $1.02 \mathrm{a}$ & $1.86 \mathrm{a}$ & $29.7 \mathrm{ab}$ \\
\hline
\end{tabular}

${ }^{\mathrm{z}}$ Branches from the upper half of the canopy.

'Branches from the lower half of the canopy.

${ }^{\mathrm{x}}$ Mean separation in columns by LSD at $P=0.05$.

between upper and lower 2-year-old limb lengths was the lowest of the six types, although significantly different only from the columnar and weeping forms (Table 2). The ratio between second year growth of upper and lower canopy limbs also showed a predominance of the latter. Semidwarf internode length was similar to standard and was the shortest of the six phenotypes. The branch angle of semidwarf was wider than all types except weeping.

Spur-type. Canopy diameter of the spur-type was similar to the others types but wider than columnar (Table 1). Branches were long and similar in length to those of semidwarf and weeping. Branch angle was comparable to standard and upright. Internode lengths were long and similar to weeping.

Upright. The upright had the greatest canopy height and width after the second year and, together with columnar, was the tallest type (Table 1). Along with the standard type, upright trees had the greatest trunk diameter. Branch angle was similar to spur-type and standard. Branch length was intermediate. Internode length was similar to columnar.

Columnar. Columnar, upright, and standard had the tallest canopies. Columnar had the narrowest canopy (Table 1). Columnar branch length and angle were similar to upright and standard, being in the shortest and narrowest class. Internode length of columnar was intermediate.

Weeping. Weeping had the shortest canopy, due to its pendulous branches, and, with semidwarf, had the narrowest trunk diameter. Branches were among the longest with spur-type and semidwarf. Internodes of weeping and spur-type were the longest of the six tree types.

Growth distribution was similar among tree forms except for weeping and columnar, which allocated relatively more shoot growth to the upper canopy (Table 2). The lower branches of standard, semidwarf, and spur-type were longer than upper limbs, and these tree forms had a tendency to allocate the new growth to the lower part of the canopy. Upright's response was intermediate (Table 2). Weeping, columnar, and upright second-year growth tended to be allocated to the upper canopy (ratio >1.0) (Table 2), although the ratio between lower and upper canopy growth was comparable to the other forms.

Determination of the number of second-order per first-order shoots showed that semidwarf, spur-type, and upright had denser branching than standard and columnar. Weeping was intermediate and columnar had the lowest branch density (Table 2). Columnar trees produced noticeably fewer second-order shoots.

\section{Response to training}

The upright and columnar trees required fewer cuts per TCSA than standard, semidwarf, and spur-type. Weeping was intermediate (Table 3). The upright and columnar growth forms required fewer cuts (because a higher percentage of cuts were of the training type) on larger limbs as opposed to cuts of smaller diameter wood, which are generally made for the purpose of cleaning trees of weak wood. Such cuts have little influence on training but many such cuts were necessary on standard, semidwarf, spur-type, and weeping trees.

\section{Fruit production}

Pruning increased yield and fruit size in standard and spur-type trees, while in semidwarf only fruit size was improved (Table 4). Only columnar and weeping fruit size was not affected by pruning because of poor yield and inherently small fruit size in weeping. Upright and weeping produced fruit with no commercial value for size and quality, while columnar showed poor cropping ability and fruit of unacceptable appearance.

\section{Shoot growth following pruning}

Only semidwarf and columnar replaced the wood removed by pruning in terms of wood grown to wood removed on the basis of grams per TCSA (Table 5). Nonpruned trees produced the same amount of new wood growth as the pruned spur-type, columnar, and weeping. The ratio of FBs to total shoot growth was lower for 
Table 3. Number of cuts per tree and amount of wood removed in pruning six peach tree growth forms (Winter 1991).

\begin{tabular}{|c|c|c|c|c|c|c|c|c|}
\hline \multirow{3}{*}{$\begin{array}{l}\text { Tree } \\
\text { form }\end{array}$} & \multirow{3}{*}{$\begin{array}{l}\text { Training } \\
\text { system }^{\mathrm{z}}\end{array}$} & & & \multicolumn{3}{|c|}{$\%$ of Total cuts } & & \\
\hline & & \multicolumn{2}{|c|}{ Cuts } & \multirow{2}{*}{$\begin{array}{c}1 \text { to } 2-y r \\
\text { limbs }\end{array}$} & \multirow{2}{*}{$\begin{array}{l}\text { Fruiting } \\
\text { branches }\end{array}$} & \multirow{2}{*}{$\begin{array}{l}\text { Weak } \\
\text { laterals }\end{array}$} & \multicolumn{2}{|c|}{ Wood removed } \\
\hline & & (no./tree) & $\left(\mathrm{no} . / \mathrm{cm}^{2}\right)^{\mathrm{y}}$ & & & & (kg/tree) & $\left(\mathrm{g} / \mathrm{cm}^{-2}\right)^{y}$ \\
\hline Standard & DV & $64 a^{x}$ & $2.13 \mathrm{a}$ & 8 & 23 & 69 & $2.48 \mathrm{ab}$ & $80 \mathrm{a}$ \\
\hline Semidwarf & DV & $49 a b c$ & $2.09 \mathrm{a}$ & 10 & 34 & 56 & $1.94 \mathrm{ab}$ & $85 \mathrm{a}$ \\
\hline Spur-type & DV & $60 \mathrm{ab}$ & $2.15 \mathrm{a}$ & 14 & 25 & 60 & $2.49 \mathrm{ab}$ & $88 \mathrm{a}$ \\
\hline Upright & SS & $45 \mathrm{bc}$ & $1.15 \mathrm{~b}$ & 18 & 31 & 51 & $3.02 \mathrm{a}$ & $75 \mathrm{a}$ \\
\hline Columnar & SS & $32 \mathrm{c}$ & $1.22 \mathrm{~b}$ & 25 & 25 & 50 & $1.47 \mathrm{~b}$ & $55 \mathrm{a}$ \\
\hline Weeping & MLS & $29 c$ & $1.76 \mathrm{ab}$ & 21 & 20 & 59 & $1.72 \mathrm{ab}$ & $92 \mathrm{a}$ \\
\hline
\end{tabular}

${ }^{\mathrm{z}} \mathrm{DV}=$ delayed vase; $\mathrm{SS}=$ slender spindle; MLS = modified lepage system.

${ }^{y}$ Number or weight of branches per trunk cross-sectional area.

${ }^{x}$ Mean separation in columns by LSD at $P=0.05$.

Table 4. Yield and mean fruit weight in the third growing season (1991) in six peach tree growth forms.

\begin{tabular}{lccccc}
\hline \hline \multirow{2}{*}{ Tree } & \multicolumn{2}{c}{ Yield } & & \multicolumn{2}{c}{ Mean fruit } \\
form & Pruned & Nonpruned & & Pruned & Nonpruned \\
\cline { 2 - 3 } \cline { 5 - 6 } Standard & $20.2 \mathrm{a}^{\mathrm{z}}$ & $12.8 \mathrm{~b}$ & & 134 & 105 \\
Semidwarf & $8.1 \mathrm{a}$ & $7.3 \mathrm{a}$ & & 120 & 99 \\
Spur-type & $15.4 \mathrm{a}$ & $8.6 \mathrm{~b}$ & & 122 & 94 \\
Upright & $17.9 \mathrm{~b}^{\mathrm{y}}$ & $27.9 \mathrm{a}$ & & 52 & 43 \\
Columnar & $4.5 \mathrm{a}$ & $4.0 \mathrm{a}$ & & 143 & 140 \\
Weeping & $1.5 \mathrm{a}$ & $1.4 \mathrm{a}$ & & 42 & 45
\end{tabular}

$\overline{{ }^{\mathrm{z}} \text { Mean separation by rows within paired columns by analysis of variance }}$ at $P=0.05$

${ }^{\text {y }}$ Mean separation at $P=0.07$

the nonpruned trees except for columnar and upright. Although nonpruned trees of columnar and upright produced as many FBs as pruned trees, upright trees produced 55\% fewer FBs than columnar trees. The pruned semidwarf and columnar produced the most FBs per unit of wood removed. Pruning was most effective in increasing FBs in weeping and standard. Weeping was intermediate and standard, spur-type, and upright produced the least.

\section{Discussion}

The six growth forms can be grouped horticulturally into three classes. The standard class consisting of standard, semidwarf, and spur-type, which were similar in shape with only small differences in height and overall architecture. Whereas fruit yield may have depressed FB growth in nonpruned trees, particularly in standard and upright, pruning increased yield and FBs in standard and spurtype. Semidwarf yield was barely affected by pruning at this early stage, but pruning stimulated the growth of many FBs, a result suggesting that fruit production may remain adequate with relatively light pruning. This fact, in addition to its reduced height, indicates that semidwarf should be more widely introduced in those breeding programs aimed at developing cultivars for MDP orchards trained to open-center vase.

Upright and columnar can be placed in another class of trees with upright canopies. Upright and columnar respond similarly to pruning, although the performance of the former was impaired by the thin branching inherited from 'NJ Pillar' and the high fruit load. The columnar form under our conditions showed promise for HDPs. Its canopy was $60 \%$ narrower (Table 1 ) and required only $50 \%$ of the cuts required to prune standard trees (Table 3). Columnar needed only light branch thinning and no major cuts compared to standard trees. Columnar trees were among the most responsive to pruning in terms of total growth and particularly growth of FBs. Even the nonpruned trees produced relatively high numbers of fruiting branches. Yet, while columnar trees seem to have potential for good fruit production, during the course of this trial they fruited poorly. Further testing and development of genotypes with improved fruit quality are required.

Table 5. Shoot growth of six peach tree growth forms following the third growing season in response to pruning after the second growing season and third season shoot growth on nonpruned trees (evaluated Mar. 1992).

\begin{tabular}{|c|c|c|c|c|c|c|}
\hline \multirow{2}{*}{$\begin{array}{l}\text { Tree } \\
\text { form }\end{array}$} & \multirow{2}{*}{$\begin{array}{c}\text { 3rd-yr growth }{ }^{\mathrm{y}} / \\
\text { wood removed }^{\mathrm{x}} \\
(\mathrm{g} / 100 \mathrm{~g})\end{array}$} & \multicolumn{2}{|c|}{$\begin{array}{c}\text { 3rd-Yr growth/ } \\
\text { TCSA }^{\mathrm{x}} \\
(\mathrm{g} / 100 \mathrm{~g})\end{array}$} & \multicolumn{2}{|c|}{$\begin{array}{c}\text { 3rd-Yr } \mathrm{FBs}^{\mathrm{z}} / \\
\text { tree wt } \\
(\mathrm{g} / 100 \mathrm{~g})\end{array}$} & \multirow{2}{*}{$\begin{array}{l}\text { 3rd-yr FBsw } \\
\text { wood removed } \\
\quad(\mathrm{g} / 100 \mathrm{~g})\end{array}$} \\
\hline & & Pruned $^{\mathrm{v}}$ & Nonpruned $^{\mathrm{u}}$ & Pruned & Nonpruned & \\
\hline Standard & 46 & $19 \mathrm{a}^{\mathrm{t}}$ & $11 \mathrm{~b}$ & $9.6 \mathrm{a}$ & $0.6 \mathrm{~b}$ & 23 \\
\hline Semidwarf & 104 & $32 \mathrm{a}$ & $23 \mathrm{~b}$ & $15.8 \mathrm{a}$ & $6.5 \mathrm{~b}$ & 53 \\
\hline Spur-type & 62 & $28 \mathrm{a}$ & $26 \mathrm{a}$ & $12.2 \mathrm{a}$ & $6.4 \mathrm{~b}$ & 17 \\
\hline Upright & 40 & $19 \mathrm{a}$ & $7 \mathrm{~b}$ & $5.3 \mathrm{a}$ & $1.1 \mathrm{a}$ & 11 \\
\hline Columnar & 122 & $28 \mathrm{a}$ & $25 \mathrm{a}$ & $11.7 \mathrm{a}$ & $10.0 \mathrm{a}$ & 55 \\
\hline Weeping & 76 & $23 \mathrm{a}$ & $26 \mathrm{a}$ & $8.2 \mathrm{a}$ & $0.2 \mathrm{~b}$ & 27 \\
\hline
\end{tabular}

${ }^{\mathrm{z} F B s}=$ fruiting branches; weight $(\mathrm{g})$ of FBs $>50 \mathrm{~cm}$.

${ }^{y}$ Weight $(\mathrm{g})$ relative to trunk cross sectional area $\left(\mathrm{cm}^{2}\right) 1$ year after pruning.

${ }^{\mathrm{x}} \mathrm{TCSA}=$ trunk cross-sectional area; weight $(\mathrm{g})$ relative to trunk cross sectional area $\left(\mathrm{cm}^{2}\right)$ the year of pruning.

${ }^{\mathrm{w}}$ Weight $(\mathrm{g})$ of fruiting branches $(\mathrm{FBs})>50 \mathrm{~cm} /$ trunk cross sectional area $\left(\mathrm{cm}^{2}\right) 1$ year after pruning.

${ }^{v}$ Six trees per growth form.

uThree trees per growth form.

${ }^{t}$ Mean separation by rows within paired columns by LSD at $P=0.05$. 
Weeping, with its unique canopy, may be of interest for new training systems, comparable to the Lepage in pear, with a zig-zag stem made from the scaffold branches alternatively positioned one above the other radiating from the trunk in all directions. As with columnar trees, weeping yield potential requires further investigation and genotypes with improved fruit quality must be developed and tested.

While this study did not compare the response of different tree forms to pruning per se, since they were not all pruned alike but in a manner appropriate to their natural growth habit, our results indicate that, by choosing the system appropriate for a particular growth habit, tree spacing and the amount of pruning can be reduced while maintaining adequate growth of vigorous wood necessary for fruit production.

Tree growth habit has received scant attention in peach breeding programs thus far, the only exceptions being the brachytic dwarf (Hansche, 1979) and semidwarf (Fideghelli et al., 1979). While cultivars with fully satisfactory horticultural habits are not yet available, the possibility of genetically manipulating canopy structure by hybridizing genotypes of differing forms has been demonstrated (Scorza et al., 1989). The present study suggests the usefulness of alternate tree forms and it indicates a need for greater insight into the physiology of growth of these tree forms to evaluate more fully their potential in orchard management. Further studies of the inheritance and interaction of the many traits involved in peach growth form still need to be conducted, including investigations of internode length, branch angle, influence of fruit size and yield on shoot growth, apical dominance, and growth regulator metabolism. The development and use of new cultivars featuring limited growth and ease of training can reduce labor requirements and growth regulator and pesticide use in peach production.

\section{Literature Cited}

Baldini, E. 1965. Corso di Arboricoltura generale. Coop. Libraria Univ. Editrice Bologna, Italy.

Corelli-Grappadelli, L. and D.C. Coston. 1991. Thinning pattern and light environment in peach tree canopies influence fruit quality. HortScience 26:1464-1466.

Corelli-Grappadelli, L. and S. Sansavini. 1991. Forme di alevamento, efficienza degli impianti e qualità delle pesche. Frutticoltura 6:13-24.

Fideghelli C., G. Della Strada, R. Quarta, and P. Rosati. 1979. Geneticsemi dwarf peach selections. Proc. Eucarpia Fruit Section on Tree Fruit Breeding, Angers, France. p. 59-66.

Fideghelli, C., G. Della Strada, andF. Grassi. 1991. Valutazione agronomica di un pescheto ad elevata densità realizzato con cultivar geneticamente nane. Frutticoltura 6:57-60.

DeJong, T.M. and J.F. Doyle. 1984. Cropping efficiency, dry matter and nitrogen distribution in mature genetic dwarf and standard peach trees. Acta Hort. 146:89-95.

Hansche, P.E. 1989. Three brachytic dwarf peach cultivars: Valley Gem, Valley Red, and Valley Sun. HortScience 24:707-709.

Hansche, P.E., C.O. Hesse, J. Beutel, W. Beres, and J. Doyle. 1979. The commercial potential of dwarf fruit trees. California Agr. 9:4-6.

Marangoni B., D. Cobianchi, M. Antonelli, A. Liverani, and D. Scudellari. 1984. The behavior of cv 'Redhaven' on different rootstocks. Acta Hort. 173:389-394.

Marini, R.P. 1985. Vegetative growth, yield, and fruit quality of peach as influenced by dormant pruning, summer pruning, and summer topping. J. Amer. Soc. Hort. Sci. 110:133-139.

Morettini, A. 1943. Un decennio di ricerche sulla potatura di produzione del pesco. Rivista Regia Società Toscana d'Orticoltura LXVIII:99-107.

Quarta, R. and M. Scortichini. 1985. Morphological characters and yielding efficiency of semi-dwarf peach selection. Acta Hort. 173:6368.

Ryugo, K. 1988. Fruit culture: Its science and art. Wiley, New York.

Scorza, R. 1988. Progress in the development of new peach tree growth habits. Compact Fruit Tree 22:92-98.

Scorza, R., G.W. Lightner, and A. Liverani. 1989. The pillar peach tree and growth habit analysis of compact x pillar progeny. J. Amer. Soc. Hort. Sci. 114:991-995.

Scorza, R., G.W. Lightner, L.E. Gilreath, and S.J. Wolfe. 1984. Reduced stature peach tree growth types: Pruning and light penetration. Acta Hort. 146: 159-163.

Scorza, R., L. Zailong, G.W. Lightner, and L.E. Gilreath. 1986. Dry matter distribution and response to pruning within a population of standard, semidwarf, compact, and dwarf peach seedling. J. Amer. Soc. Hort. Sci. 111:541-545. 